\title{
CORRESPONDENCE
}

\section{The Asthma Control Questionnaire for children: still more questions than answers}

\section{To the Editors:}

Optimising control is the main goal in paediatric asthma management and reliable instruments that can help physicians to evaluate asthma control in an easy way are valuable. The article by JUNIPER et al. [1] provides some initial insights on the use of the Asthma Control Questionnaire (ACQ), an instrument that was originally developed for adult asthma, to assess asthma control in children. The process of developing and validating such a questionnaire is a delicate one. In 2009 JUNIPER [2] published a critical editorial about the consequences of even small modifications to original questionnaires and how this could influence the validity of these instruments. Therefore, we were surprised to see that despite her previous exposé [2], in the current paper JUNIPER et al. [1] pooled observations from two different versions of the ACQ (i.e. one version for children up to 10 yrs of age and one version for older children and teens) in one validation study. Essential differences between these ACQ versions are the type of administration (interviewer versus written assessment), the wording (i.e. for the younger children alternative wording and instructions were available) and parental help being allowed for the youngest children. Based on previous research, differences in reliability of scores between the younger and older group of patients could be expected [3]. In the current article all outcomes were clustered and favourable results for the older children and teens may mask problems that exist in the youngest group, or vice versa. Therefore, separate validation for these two age-related questionnaires would seem inevitable.

Lack of standardisation could hamper the within-subject reliability as well as the between-subject reliability of a questionnaire. In the ACQ version for the younger group this could be a problem because rephrasing can result in different responses from the same child and parents may interpret and score ACQ questions differently from their child. These two potential threats of reliability should have been evaluated and eliminated before this mixed methods approach in the questionnaire for the younger group could be considered as a valid method of assessing asthma control. Moreover, this evaluation should be performed in a much bigger sample of children than the nine children included in the developmental phase of the instrument [4].

In our view, further studies that separately evaluate these two different versions of the ACQ are needed before the ACQ should be considered as a reliable tool to evaluate asthma control in children. New studies are essential as the sample described in the article (35 children) seems far too small to perform subgroup analyses. Also, additional information about the validity of the mixed methods approach that was used in the ACQ version for the younger children is needed. Inaccurate measurement of asthma control could lead to misinformed treatment decisions and/or inaccurate conclusions in future scientific papers. Although the first results of JUNIPER et al. [1] are very promising, these issues need to be addressed before the ACQ can be considered as a valid tool to assess control in paediatric asthma.

\section{L. van den Bemt, S. van Bragt and T. Schermer}

Dept of Primary and Community Care, Radboud University, Nijmegen Medical Centre, Nijmegen, The Netherlands.

Correspondence: L. van den Bemt, Dept of Primary and Community Care, Centre for Family Medicine, Geriatric Care and Public Health (route 117), Radboud University, Nijmegen Medical Centre, PO Box 9101, 6500 HB, Nijmegen, the Netherlands. E-mail: L.vandenBemt@elg.umcn.nl

Statement of Interest: None declared.

\section{REFERENCES}

1 Juniper EF, Gruffydd-Jones K, Ward S, et al. Asthma Control Questionnaire in children: validation, measurement properties, interpretation. Eur Respir J 2010; 36: 1410-1416.

2 Juniper EF. Validated questionnaires should not be modified. Eur Respir J 2009; 34: 1015-1017.

3 Juniper EF, Guyatt GH, Feeny DH, et al. Measuring quality of life in children with asthma. Qual Life Res 1996; 5: 35-46.

4 Juniper EF, Gruffydd-Jones K, Ward S. Developing an intervieweradministered version of the asthma control questionnaire (ACQ) for children $\leqslant 10$ years. Eur Respir J 2007; 30: Suppl. 51, 382s.

DOI: $10.1183 / 09031936.00189610$

\section{From the authors:}

L. van den Bemt and co-workers raise an important issue concerning the use of both self- and interviewer-administered versions for the validation of the Asthma Control Questionnaire (ACQ) in children and one we considered carefully when designing the study. We wanted to ensure that the ACQ could be used in clinical practice (individual children followed over time), paediatric research (6-16 yrs) and adult research $(\geqslant 12$ yrs). Therefore, two separate questionnaires was not an option. The development of the ACQ had ensured that it contained the questions that are important for assessing asthma control in children $6-16$ yrs of age (content validity) but we knew the self-administered adult version could not be completed unaided by younger children. We considered 
validating an interviewer version for all ages (6-16 yrs) but realised this would be less practical for older children and also for adult clinical trials that enrol patients $\geqslant 12$ yrs of age. The decision to develop an interviewer version for younger children (and for older children with inadequate literacy or numeracy skills) that could be combined with data from the self-administered version was based on strong evidence [1, 2]. Nevertheless, to minimise further any risk of bias, which might have affected the estimation of the measurement properties, children were consistent in the version they completed. L. van den Bemt and co-workers cited our validation of the Paediatric Asthma Quality of Life Questionnaire as evidence that within- and between-subject variance differs across age groups [3]. In that study, within-subject variance was very consistent across all age groups. Between-subject variance was consistent in the 7-10-yr and 15-17-yr groups but higher in the 11-14-yr group, suggesting that there was a wider range of impairment in the middle group. This does not mean that reliability, responsiveness or validity of the instrument were different in the different age groups; they were actually very similar.

Addressing the concern about ACQ interviewer instructions and parental help, we could have asked interviewers to read the self-administered version to younger children and given no guidance about parental involvement (which happens with many other questionnaires). This approach is open to errors. Although children as young as 6 yrs old understand the 7 -point scale and can give very reliable responses [4, 5], they need the responses on a card and the concept explained in a standardised manner. For children $<8$ yrs of age, the concept of "during the last week" is also difficult and interviewers have to know how to check this. Interviewers first read each question to all children exactly as it is written in the original ACQ. However, we found during cognitive debriefing that a few of the youngest children did not understand some of the questions very accurately. We could have left it to interviewers to explain these questions. This is the usual approach but interviewers sometimes do not fully understand the concepts themselves and give an erroneous interpretation. To minimise this source of error, we give standardised alternative wording (interestingly, this novel approach has raised a new methodological challenge as the interviewer version is adapted for new languages: the questions that are difficult for young children to understand vary between languages). Ideally, one would like children to respond to all the questions but they sometimes need a bit of help. Although parents and primary caregivers often have a poor perception of their child's asthma-related quality of life, their perception of their clinical asthma status is better [6]. We tried to use their input as little as possible but it was sometimes required for question 6 concerning the number of puffs of rescue bronchodilator used each day.
For patient-reported outcomes (PROs) there is rarely a "gold standard" with which to compare the new instrument for evidence of validity. Construct validity is the building up of evidence that the instrument is measuring what it purports to measure. In this study, we have provided the first evidence of the validity of the ACQ in children. Not only did the instrument give good measurement properties that were similar to those observed in adults (important for the use of the ACQ in adult ( $\geqslant 12$ yrs of age) studies), the fact that these were observed in a relatively small sample size strengthens the evidence of validity rather than weakens it. Nevertheless, we agree that, like all other PROs, construct validity grows with additional studies and we would welcome further evaluation of this instrument. In addition, for adults, we have determined the cut-point on the ACQ score between adequate and inadequate asthma control, and this must now be established for children.

\section{E.F. Juniper*, K. Gruffydd-Jones ${ }^{\#, \oplus,+}$, S. Ward ${ }^{\#}$ and K. Svensson ${ }^{\S}$}

*Dept of Clinical Epidemiology and Biostatistics, McMaster University, Hamilton, Canada. "Box Surgery and "University of Bath, Bath, and 'University of Aberdeen, Aberdeen, UK. ${ }^{\S}$ HEOR Consulting, Lund, Sweden.

Correspondence: E.F. Juniper, 20 Marcuse Fields, Bosham, West Sussex, PO18 8NA, UK. E-mail: juniper@qoltech.co.uk

Statement of Interest: Statements of interest for E.F. Juniper and K. Gruffydd-Jones can be found at www.erj.ersjournals. com/site/misc/statements.xhtml

\section{REFERENCES}

1 Juniper EF, Guyatt GH, Ferrie PJ, et al. Measuring quality of life in asthma. Am Rev Respir Dis 1993; 147: 832-838.

2 Juniper EF, Buist AS, Cox FM, et al. Validation of a standardized version of the Asthma Quality of Life Questionnaire. Chest 1999; 115: 1265-1270.

3 Juniper EF, Guyatt GH, Feeny DH, et al. Measuring quality of life in children with asthma. Qual Life Res 1996; 5: 35-46.

4 Juniper EF, Guyatt GH, Feeny DH, et al. Minimum skills required by children to complete health-related quality of life instruments for asthma: comparison of measurement properties. Eur Respir J 1997; 10: 2285-2294.

5 Juniper EF, Howland WC, Roberts NB, et al. Measuring quality of life in children with rhinoconjunctivitis. J Allergy Clin Immunol 1998; 101: 163-170.

6 Guyatt GH, Juniper EF, Feeny DH, et al. Children and adult perceptions of childhood asthma. Pediatrics 1997; 99: 165-168.

DOI: 10.1183/09031936.00005311 